\title{
SETDB1 in Early Embryos and Embryonic Stem Cells
}

\section{Yong-Kook Kang}

Development and Differentiation Research Center, KRIBB, 111 Gwahang-ro, Yuseong-gu, Daejeon 305-806, South Korea E-mail: ykkang@kribb.re.kr

DOI: http://dx.doi.org/10.21775/cimb.017.001

\begin{abstract}
The histone methyltransferase SETDB1 contributes to the silencing of local chromatin and the target specificity appears to be determined through various proteins that SETDB1 interacts with. This fundamental function endows SETDB1 with specialized roles in embryonic cells. Keeping the genomic and transcriptomic integrity via proviral silencing and maintaining the pluripotency by repressing the differentiation-associated genes have been demonstrated as the roles of SETDB1 in embryonic stem cells. In early developing embryos, SETDB1 exhibits characteristic nuclear mobilizations that might account for its pleiotropic roles in these rapidly changing cells as well. Early lethality of SETDB1-null embryos, along with other immunolocalization findings, suggests that SETDB1 is necessary for reprogramming and preparing the genomes of zygotes and pluripotent cells for the post-implantation developmental program.
\end{abstract}

\section{Introduction}

SETDB1 (SET domain, bifurcated 1), also known as ESET/ KMT1E, is a histone $\mathrm{H} 3$ lysine 9 (H3K9)-specific methyltransferase that is involved in the transcriptional silencing of euchromatic genes. Since it was identified via its interaction with $\mathrm{Erg}$ in a yeast two-hybrid screen (Yang et al., 2002), SETDB1 has been shown to bind to various proteins, including KAP-1 (Schultz et al., 2002), SP3 (Stielow et al., 2008), mAM (Wang et al., 2003), DNMT3A ( $\mathrm{Li}$ et al., 2006), OCT4 (Yeap et al., 2009; Yuan et al., 2009), and the MBD1/CAF-1 chaperone complex (Loyola et al., 2009; Sarraf and Stancheva, 2004), which suggests that SETDB1 is involved in multiple biological processes. In support of this suggestion, recent studies demonstrate that SETDB1 is necessary for proviral silencing and the selfrenewal and lineage specification of embryonic stem cells (ESCs). In addition, SETDB1 is attracting increasing interest owing to its genic amplification and therefore increased expression in patients with melanoma (Ceol et al., 2011; Macgregor et al., 2011) and in lung cancer cells (Rodriguez-Paredes et al., 2013). SETDB1 has also been implicated in neural diseases and development (Chase et al., 2013; Ryu et al., 2006; Tan et al., 2012). Given these findings, the role of SETDB1 is likely to be distinct from that of other H3K9-specific methyltransferases, such as SUV39H1, GLP, and G9A. Briefly, SUV39H1 (also known as KMT1A) is crucial for the establishment of pericentric and telomeric heterochromatin (Peters et al., 2003; Peters et al., 2001; Schotta et al., 2002) and for rDNA silencing (Peng and Karpen, 2007). G9A (also named Eu-HMTase2/ KMT1C), forms a heterodimer with GLP (Ueda et al., 2006), which methylates not only H3K9 but also a number of non-histone substrates, including p53, ACINUS, and LEPTIN (Huang et al., 2010; Lee et al., 2010; Rathert et al., 2008), and also functions in germ cell development (Tachibana et al., 2007). Hence, these methyltransferases seem to methylate different genomic regions and be involved in distinct cellular processes, although there are likely to be collaborations between them in some circumstances (Brower-Toland et al., 2009; Fritsch et al., 2010; Yoon et al., 2008).

SETDB1 is a genome-wide chromatin modifier that achieves target specificity via its protein partners. Hence, the existing data on SETDB1 function are, in reality, focused on the regulation of gene expression by transcription factors. However, several lines of evidence suggest that SETDB1 is involved also in other cellular processes than the transcriptional regulation. For example, SETDB1 is an essential structural component of promyelocytic leukemia-nuclear body (PML-NB) (Cho et al., 2011), which is a large proteinaceous structure involved in many diverse cellular processes (reviewed in (Bernardi and Pandolfi, 2007; de The et al., 2012)). Two studies have reported that SETDB1 is localized partly in the cytoplasm and partly in the nucleus (Cho et al., 2013; Loyola et al., 2006). Taken together, the evidence suggests that SETDB1 has additional roles that remain uncharacterized. Here, I will discuss the behavior and the possible function of SETDB1 in cells in early developmental stages, including preimplantation-stage embryos and their derivative pluripotent stem cells, focusing on the immunocytochemical observations, which provide insights into the roles of SETDB1. The molecular mechanisms of gene repression by SETDB1 are outside the scope of this article.

\section{Structural features in SETDB1}

A protein's structure is predictive of its behavior. SETDB1 has a structure composed of evolutionarily conserved SET, pre-SET, and post-SET domain responsible for histone methylation (Rea et al., 2000) (Fig. 1A). The pre- and postSET domains are necessary for SET domain catalytic activity (Schultz et al., 2002). As denoted in the name of the protein, the SET domain of SETDB1 is interrupted by the insertion of several hundred amino acids. Such a split in the SET domain is unique to SETDB1 and is conserved across organisms including humans, worms, and flies. It is currently unknown whether this intervening sequence is required for the catalytic activity of SETDB1, has a particular role in SETDB1 function, or is simply a way of bringing the two parts of split SET domain closer together.

SETDB1 also possesses a putative methyl-CpG- 

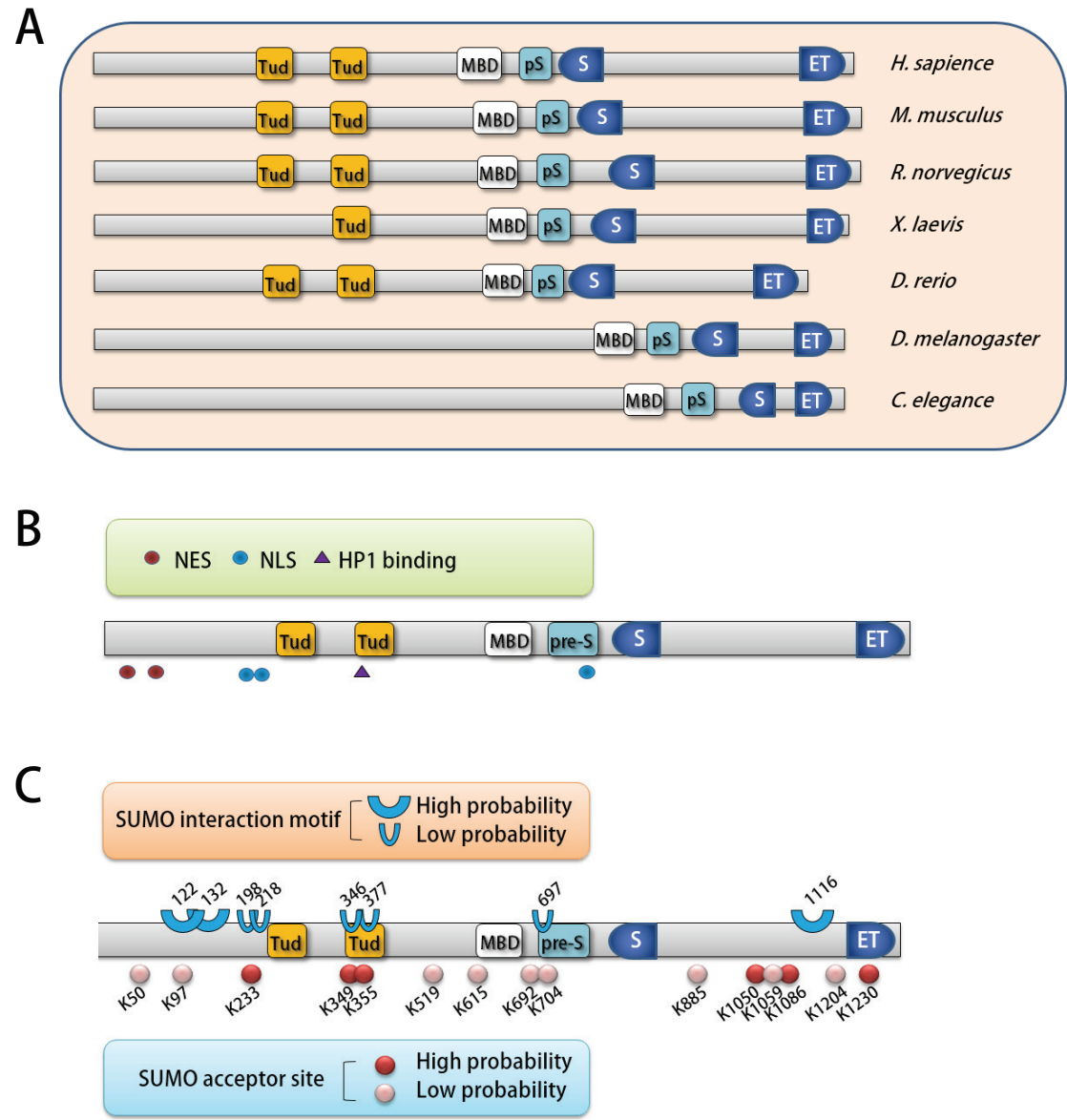

Figure 1. Structure of the SETDB1 protein. A, Bifurcated SET domains conserved in SETDB1 proteins of different species. The SET domain is split in all species examined. Tud, Tudor domain; MBD, methyl-CpG-binding domain; pS, pre-SET domain; S and ET, bifurcated SET. Post-SET domain is not shown. B-C, Functional motifs in mouse SETDB1. In B, both nuclear localization signal (NLS) and nuclear export signal (NES) are indicated. An HP1 binding motif (PxVxL) is also seen. In C, SUMO interaction motif (SIM) and SUMO acceptor site (SAS) are denoted, each classified to high or low probability (score $>6.0$ and $>0.7$ for SIM and SAS, respectively, according to the GPS-SBM program).

binding domain (MBD) and two consecutive Tudor domains. The MBD domain of SETDB1 is of particular interest because it represents the intra-molecular coupling of a methyl-CpG 'reader' to the H3K9 methylation 'writer', suggesting an interdependent mechanism for the establishment and/or propagation of these two epigenetic marks. However, it remains unknown whether the MBD of SETDB1 can selectively bind methylated DNA. Notably, the MBD domain of SETDB1 contains two DNA-interacting arginine residues that are conserved in the MBD domains of MBD1 (Ohki et al., 2001) and MeCP2 (Ho et al., 2008), suggesting that the MBD domain is functional.

Tudor domain proteins are functionally assigned to bind methylated arginine or lysine residues on both histone and non-histone substrates and are implicated in diverse biological processes including RNA metabolism and germ cell development (reviewed in (Chen et al., 2011; Siomi et al., 2010)). The Tudor domain of SETDB1 in mammals is present in a tandem double configuration (Fig. 1A) and, like other double Tudor domain proteins, is thought to recognize certain type(s) of histone lysine methylation. For example, JMJD2A/JHDM3A is a histone demethylase specific for $\mathrm{H} 3 \mathrm{~K} 9 \mathrm{me} 3$ and $\mathrm{H} 3 \mathrm{~K} 36 \mathrm{me} 3$ that binds to H3K4me3 (Huang et al., 2006), and mammalian p53 binding protein (53BP1), which is implicated in DNA damage repair, binds to H4K20me1 and H4K20me2 (Botuyan et al., 2006), also reviewed in (Pek et al., 2012; Taverna et al., 2007). The double Tudor domains of SETDB1 might be required for binding to chromatin with double strength, or may bind different histone modifications (Botuyan et al., 2006), each with distinct preference to a certain ligand. It remains unknown which lysine residue(s) and which state(s) of lysine methylation the Tudor domains of SETDB1 recognize, or whether a totally different role is played by these domains.

\section{Nuclear SETDB1 and cytoplasmic SETDB1}

Microscopic observations suggest that transcriptional regulation via promoter methylation may not be the only function of SETDB1. Immunostaining of SETDB1 in 


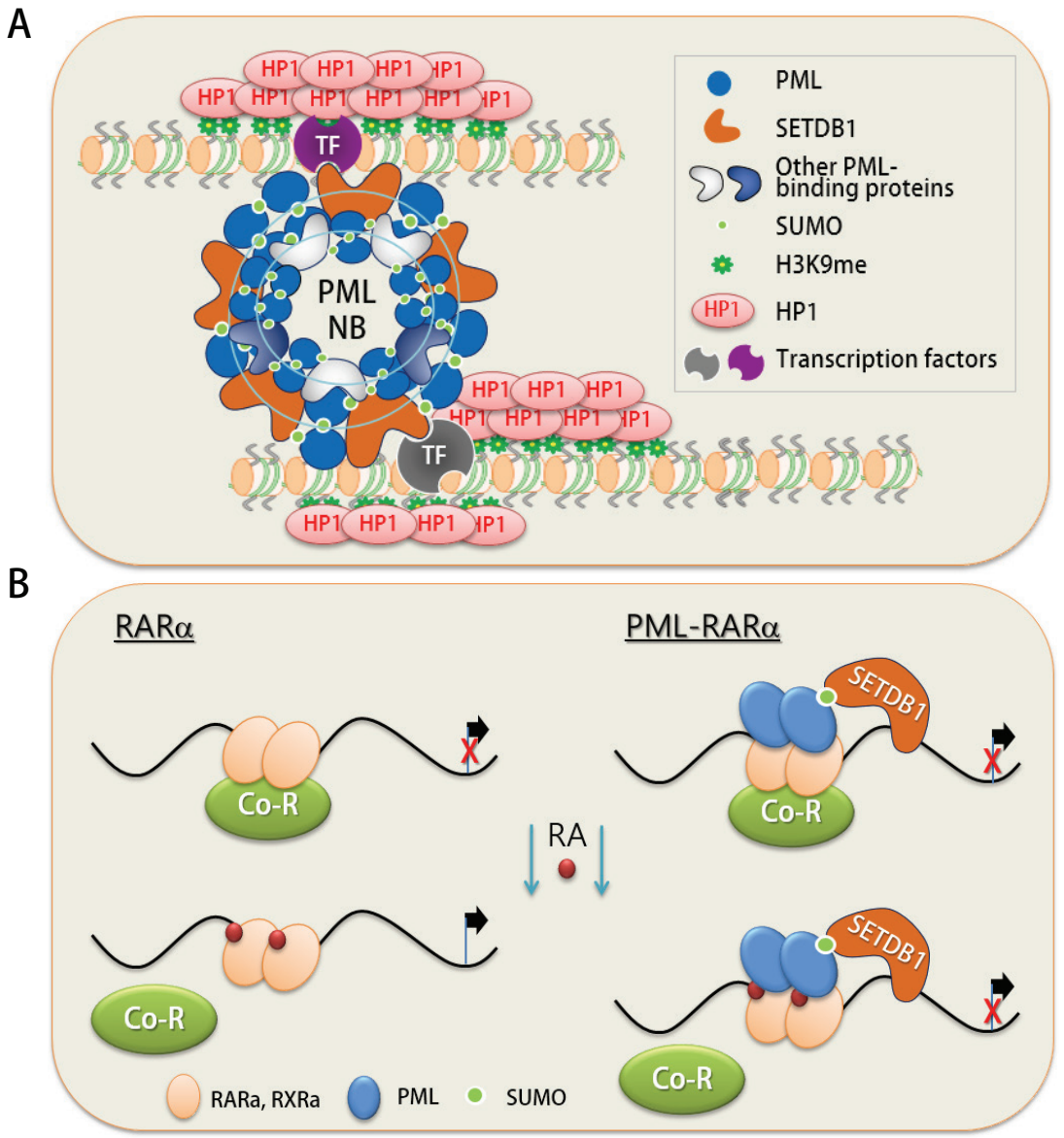

Figure 2. Interaction of SETDB1 with PML. A, SETDB1 in PML nuclear body (PML-NB). As an essential component of PML-NB structure, SETDB1 is hypothesized to be guided to targets by transcription factors (TF) and anchor itself onto target chromatin via its double Tudors and/or MBD domain. SETDB1 adds H3K9me3 and subsequently recruits HP1. PML-NB is stabilized through SUMO-SIM interactions. B, A hypothetical interaction between SETDB1 with PML-RARa fusion protein in acute promyelocytic leukemia (APL) cells. RARa as a dimer works together with corepressor (Co-R) to repress expression of a target gene. In the presence of retinoic acid (RA), RARa dimer releases co-repressor and shifts to express the target gene. However, the PML-RARa fusion protein, the PML moiety of which interacts with SETDB1, has a great difficulty relieving the chromatin to a transcription-permissive state after exposure to RA owing to SETDB1 activity as a transcription suppressor.

cultured cells revealed distinct modes of distribution in the nucleus-a diffuse (Schultz et al., 2002) and a punctate pattern (Cho et al., 2011; Yeap et al., 2009), which are not mutually exclusive and may co-exist in the same nucleus. The diffuse pattern fits with the known function of SETDB1 as a global transcriptional repressor that acts on the entirety of a cell's euchromatin. On the other hand, the punctate localization suggests an unknown role. Some studies have shown that punctate SETDB1 localization corresponds to PML-NB foci ((Cho et al., 2011; Cho et al., 2013), and see below), and a separate study showed that SETDB1 moves to pericentric heterochromatin displaying spot signals in a cell cycle-dependent manner (Loyola et al., 2009). This discrepancy in SETDB1 localization might be caused by different functions of the protein, or the existence of different SETDB1 variants (Blackburn et al., 2003).
The expression of epitope-tagged SETDB1 was monitored in an attempt to explain the discordant observations of endogenous SETDB1. However, this attempt unexpectedly revealed that over-expressed SETDB1 was largely located in the cytoplasm (Cho et al., 2013). Treatment with leptomycin B-a Crm1 inhibitor that can block protein export from the nucleus (Wolff et al., 1997)_provided an explanation for the cytoplasmic retention of SETDB1: the cytoplasmic GFP-bound SETDB1 proteins could partly enter the nucleus and remain bound at PML-NB foci or scattered in the nucleoplasm but even those that succeed in entering the nucleus become exported in a Crm1-dependent mechanism (Cho et al., 2013). Thus, nuclear entry and residence of exogenous SETDB1 is tightly regulated. Human SETDB1 has been predicted to contain two nuclear export signals (NESs) and two nuclear localization signals (NLSs) in its amino terminal 


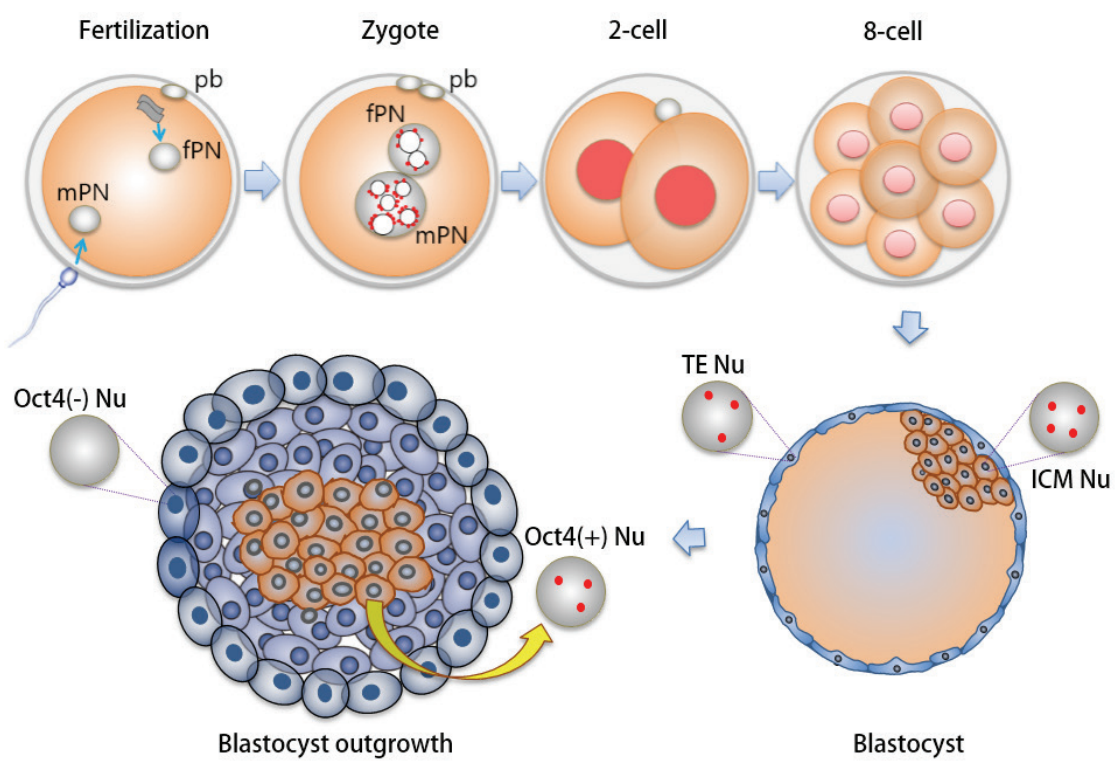

Figure 3. Mobilization of SETDB1 during early mouse development. Shortly after fertilization, SETDB1 expression is unclear. In the mid to late pronucleus stage in zygote, SETDB1 is detected as discrete, discontinuous dots at the pronucleolar rims. From the 2-cell stage, the SETDB1 signal takes a diffuse pattern in the nucleus with the intensity decreasing gradually. In the blastocyst, SETDB1 rearranges to form condensed foci in the nucleus $(\mathrm{Nu})$, which coincide with PML (Cho et al., 2011), and distributes to the inner cell mass (ICM) and trophectoderm (TE) cells uniformly. Finally, in blastocyst outgrowths, SETDB1 is detected only in Oct4-positive cells of ICM origin. pb, polar body; mPN and fPN, male and female pronucleus.

region (Fig. 1B), making the nucleocytoplasmic shuttling of SETDB1 feasible. These motifs are also found in mouse SETDB1 at the preserved positions (Cho et al., 2013), and removal of the $\mathrm{N}$-terminal region containing these motifs perturbs the cytoplasmic retention of SETDB1, resulting in ubiquitous expression both in the nucleus as well as the cytoplasm. Furthermore, cell fractionation experiments demonstrated that endogenous SETDB1 is both cytoplasmic and nuclear (Cho et al., 2013; Loyola et al., 2006), whereas G9A/GLP and SUV39H1 are localized to the nucleus only (Loyola et al., 2006). Thus, the cytoplasmic function of endogenous SETDB1 must be unrelated with the functions of G9A/GLP and SUV39H1. The reasons why overexpressed SETDB1 is retained in the cytoplasm, and in what condition the detained SETDB1 reenters the nucleus, are unclear.

\section{SETDB1 in PML nuclear bodies}

PML-NB is involved in a broad range of biological processes such as the induction of cellular senescence and apoptosis, the antiviral response, and the maintenance of genome stability, through interaction with diverse proteins with distinct functions (Bernardi and Pandolfi, 2007; de The et al., 2012). PML and SETDB1 are the only essential constituents of the PML-NB structure; without either of these two, PML-NB does not form (Cho et al., 2011; Ishov et al., 1999; Zhong et al., 2000). SETDB1 knockdown causes the loss of PML-NB foci, and arsenic $\left(\mathrm{As}_{2} \mathrm{O}_{3}\right)$ treatment, which induces PML degradation (for review, see (Lallemand-Breitenbach et al., 2012)), causes the loss of the SETDB1 signal. The structural relationship between SETDB1 and PML-NB suggests that SETDB1 is involved in some, if not all, of the functions of PML-NB.

Small ubiquitin-related modifiers (SUMOs) are necessary for PML-NB formation (Kamitani et al., 1998; Zhong et al., 2000) and act as intermediaries between SETDB1 and PML (Cho et al., 2013; Yeap et al., 2009). Most PML-NB-associated proteins have SUMO acceptor sites, are therefore SUMOylated (Muller et al., 1998; Shen et al., 2006), and contain SUMO-interaction motifs (SIMs, (Ivanov et al., 2007)), which are essential for targeting PML-NB (Cho et al., 2009; Lin et al., 2006). SETDB1 contains several candidate sites for both motifs (Fig. 1C). SETDB1 mutated at a single SIM site showed reduced interaction with PML and disturbed the formation of PMLNB (Cho et al., 2013), which indicates that the SIM motif of SETDB1 is necessary for its association with PML. It has been hypothesized that SETDB1 proteins anchor themselves onto target chromatin via the double Tudor domains or MBD domain and, at the same time, hold the PML-NB complex together tightly through SUMO-SIM interactions (Fig. 2A). Of the several tens of proteins hitherto found to be part of PML-NB, SETDB1 appears only to form, with the aid of heterochromatin protein 1 (HP1), a solid platform of heterochromatin to which PML-NB can be riveted. SETDB1-mediated local heterochromatin formation involves a self-reinforcing mechanism in which SETDB1produced H3K9me3 marks recruit HP1 proteins, which are then bound by SETDB1. Accordingly, HP1 localizes at PML-NB foci (Luciani et al., 2006; Seeler et al., 1998). 
SETDB1 proteins also participate in the repression of PML target genes such as Id2 (Cairo et al., 2005) through H3K9trimethylation in the promoter region, which prevents binding of RNA polymerase II (Cho et al., 2011). Therefore, embedding in PML-NB, SETDB1 appears to fulfill dual functions - the maintenance of the structural integrity of PML-NB and the transcriptional control of PML-NBassociated genes.

\section{SETDB1 in early development}

Mouse embryos that lack functional Setdb1 die around peri-implantation (approximately embryonic day 4.5 (E4.5) (Dodge et al., 2004). The loss of SETDB1 causes earlier lethality than that of other H3K9 methyltransferases, such as SUV39H1 (nonessential; (Peters et al., 2001)), G9A (mutant embryos die around E9.5); (Tachibana et al., 2002)), and GLP (mutant embryos die around E9.5; (Tachibana et al., 2005)). This indicates that these functionally redundant enzymes, though expressed in blastocysts (Cho et al., 2011), cannot compensate for the loss of Setdb1, which highlights the uniqueness and the significance of SETDB1 function in early mouse development. Accordingly, SETDB1 is more abundant in the mouse oocyte than G9A and SUV39H1 are (Cho et al., 2011; Cho et al., 2012).

Immunofluorescence revealed that after fertilization, SETDB1 gradually appears in the pronucleus, with the stronger signal in the male pronucleus than the female pronucleus (Cho et al., 2012) (Fig. 3). It leads to a speculation that SETDB1 may participate in the reconfiguration of sperm-derived chromatin. SETDB1 at this stage is observed in discontinuous spots in the perinucleolar region, where satellite DNA sequences localize and constitute heterochromatin (Martin et al., 2006). Given that sperm-derived chromatin remains unmodified at $\mathrm{H} 3 \mathrm{~K} 9 \mathrm{me} 3$ throughout the pronucleus stage (Arney et al., 2002; Liu et al., 2004; Park et al., 2007), the unique perinucleolar expression of SETDB1 seems irrelevant. A possible explanation is that SETDB1 is drawn to this region due to its ability to interact with HP1 that resides at the pronuclear nucleolar rims (Arney et al., 2002; Santos et al., 2005). Several studies in culture cells have shown that SETDB1 is funneled onto these HP1-enriched regions (Ayyanathan et al., 2003; Verschure et al., 2005), probably via the PxVxL motif (Thiru et al., 2004) of SETDB1 that is conserved between mouse and human (PM는; Fig. 1B). If so, it would be interesting to know the mechanism by which HP1 occupies the H3K9me2/me3-deficient nucleolar rims and the role of SETDB1 recruitment. It is worth noting that HP1 binds the H3 histone-fold (Billur et al., 2010; Lavigne et al., 2009; Nielsen et al., 2001; Zhao et al., 2000) independently of H3K9 methylation (Dialynas et al., 2006; Figueiredo et al., 2012).

The spotted SETDB1 signal around the nucleolus is transiently maintained until the 2-cell stage when the signal becomes a diffuse pattern (Cho et al., 2012) (Fig. 3). Diffuse SETDB1 expression persists until the 8-cell stage, then temporarily fades (Cho et al., 2011; Dodge et al., 2004) before appearing again in a dotted form in the blastocyst (Cho et al., 2011). At this time, SETDB1 localizes to PML-NB foci, indicating that the SETDB1-PML interaction commences at the preimplantation stage. Thus, the timing of the beginning of SETDB1-PML interaction coincides with the timing of the occurrence of developmental failure in Setdb1-null embryos, which may imply a cause-and-effect relationship between the two events. However, such a relationship is unlikely considering the full-term viability of Pml-null mouse embryo (Wang et al., 1998a; Wang et al., 1998b).

The varying patterns of SETDB1 mobilization during the preimplantation development suggests multiple roles of SETDB1 in this stage that might depend on its interactions with other proteins. Protein-protein interactions might occur via SUMOs. SUMO-involved interaction is not likely to occur with G9A and SUV39H1; a motif-search program (GPS-SBM) predicts that SETDB1 has several SIM and SUMOylation sites whereas G9A and SUV39H1 have no and far fewer sites, respectively (unpublished observation). However, the cellular processes in which SETDB1 is involved, and the consequence of the SETDB1 repositioning are unknown. Nevertheless, given its fundamental function as an epigenetic modifier and its abundant activity in early embryos compared with related proteins, SETDB1 is thought to play a pivotal role in reprogramming and preparing the zygotic genome for the post-implantation developmental program.

\section{SETDB1 in embryonic stem cells}

Blastocysts consist of an inner cell mass (ICM) and trophectoderm (TE) cells, which develop into the embryonic and the extraembryonic (trophoblast) lineages, respectively (Rossant, 2004). ESCs can be established in vitro by extended culture of ICM cells via blastocyst outgrowth. In mouse blastocysts, a punctate pattern of SETDB1 localization is seen in the nuclei of the ICM and the TE compartments (Fig. 3) (Cho et al., 2012). However, in blastocyst outgrowths, the punctate pattern is maintained only in ICM-derived Oct4-positive cells while it is lost in the surrounding cells of TE origin (Cho et al., 2012) (Fig. 3). The punctate SETDB1 expression observed in blastocyst outgrowths continues in established mouse ESCs (Cho et al., 2012; Yeap et al., 2009). Consistent with the report that Setdb1-null blastocysts fail to give rise to ESCs in vitro (Dodge et al., 2004), this observation suggests a role of this specific mobilization of SETDB1 in the establishment and/or maintenance of ESCs.

SETDB1 knockdown in ESCs resulted in the loss of the normal colony morphology and the Oct4 expression, which then accompanies the expression of various differentiation markers (Cho et al., 2012; Yeap et al., 2009; Yuan et al., 2009). Immunoprecipitation (IP) experiments demonstrated the physical interaction of SETDB1 with Oct4 in mouse ESCs (Cho et al., 2012; Yeap et al., 2009; Yuan et al., 2009). In addition, ESCs with reduced SETDB1 level, when they were aggregated into 2-cell embryos, populate exclusively to the TE rather than the ICM during in vitro development (Yuan et al., 2009). This change in cell fate appears to be intimately related to the induced expression of extraembryonic lineage-specific genes, such as $C d \times 2$ (Strumpf et al., 2005) and Tcfap2a (Auman et al., 2002). Consistently, Oct4-associated SETDB1 was shown to bind to the promoters of $C d x 2$ and Tcfap2a genes, resulting in the transcriptional repression (Yeap et al., 2009; Yuan et al., 2009). Thus, it is likely that the role of SETDB1 in 
keeping ESCs from differentiation to the trophoblast lineage has to do with its ability to repress the genes that are essential for trophoblast development.

SETDB1 contributes to the establishment of global $\mathrm{H} 3 \mathrm{~K} 9 \mathrm{me} 3$ landscape in ESCs. Most genes in mouse ESCs have $\mathrm{H} 3 \mathrm{~K} 4 \mathrm{me} 3$-modified nucleosomes, as in human ESCs (Guenther et al., 2007; Kim et al., 2005), and one-fifth of these $\mathrm{H} 3 \mathrm{~K} 4 \mathrm{me} 3$-occupied genes are also occupied by $\mathrm{H} 3 \mathrm{~K} 9 \mathrm{me}$. SETDB1 binding has been detected in about one-fifth of $\mathrm{H} 3 \mathrm{~K} 9 \mathrm{me} 3-\mathrm{occupied}$ genes (Bilodeau et al., 2009). SETDB1 and H3K9me3 co-occupy and suppress a subset of the bivalent genes that are known to harbor $\mathrm{H} 3 \mathrm{~K} 4 \mathrm{me} 3-$ and H3K27me3-enriched nucleosomes in their promoters and that frequently encode developmental regulators (Bilodeau et al., 2009; Yuan et al., 2009). This observation indicates that, in addition to the trithorax group (TrxG)-given H3K4me3 and PcG-provided H3K27me3, SETDB1 provides the developmental regulator genes with an additional layer of the repressive mark H3K9me3.

SETDB1 is also involved in silencing the endogenous retroviruses (ERVs), especially ERV class-I and -II, in ESCs. Retrotransposition that a subset of class-I and -II ERVs makes is responsible for almost $10 \%$ of all spontaneous mutations in mice (Maksakova et al., 2006). DNA methylation has an important role in ERV silencing in somatic cells and germ-lineage cells (Bourc'his and Bestor, 2004; Walsh et al., 1998; Yoder et al., 1997) but not in ESCs where the proviral genomes are featured for H3K9me3 (Mikkelsen et al., 2007). It has been shown that SETDB1 is recruited by Krüppel-associated box (KRAB)associated protein (KAP1) and modifies the proviral genome with H3K9me3 (Matsui et al., 2010). SETDB1 depletion in ESCs resulted in not only the loss of H3K9me3 but also the induction of IAP, MLV, and MusD transcription. Interestingly, DNA methylation states at these ERV loci remain unaltered (Matsui et al., 2010), indicating that proviral silencing in ESCs occurs independently of DNA methylation (Leung and Lorincz, 2012; Pannell et al., 2000). These ERVs are not expressed in Dnmt1---Dnmt3a-/Dnmt3b-/- triple knockout ESCs (Tsumura et al., 2006) where they are completely demethylated at $\mathrm{CpG}$ dinucleotides (Matsui et al., 2010). This type of proviral silencing is ESC-specific (Mikkelsen et al., 2007); ERV derepression does not occur in SETDB1-depleted mouse embryonic fibroblasts (Matsui et al., 2010). Proviral silencing is also SETDB1-specific; G9a ${ }^{-/-G L P} P^{-/-}$(Tachibana et al., 2005) or Suv39h1--Suv39h2-/- (Peters et al., 2003) double knockout ESCs are unable to derepress these ERVs (Matsui et al., 2010). A recent study found that G9A and GLP, but not SETDB1, are required to suppress the class-III ERVs including MERVL (Maksakova et al., 2013). A subset of genes that are upregulated in SETDB1depleted ESCs are involuntarily transcribed via derepression of promoter-proximal ERVs, and some of them generate LTR-genic chimeric transcripts (Karimi et al., 2011). Thus, aberrant expression of ERVs could alter the expression of neighboring genes. Part of these ERVinitiated genes act as proto-oncogenes, which transform host cells (Howard et al., 2008; Lamprecht et al., 2010; Lee et al., 1999). Thus, SETDB1 in ESCs plays an important role in keeping the genomic and transcriptomic integrity through the ERV silencing mechanism.

\section{Perspective}

After fertilization, the embryonic genomes undergo a series of remarkable epigenetic changes. Epigenetic modifiers such as SETDB1 reconfigure the genomic structure of developing embryos, and are central to reprogramming in this early period. SETDB1 is highly expressed throughout the preimplantation period and is thought to be the major protein that regulates $\mathrm{H} 3 \mathrm{~K} 9$ methylation of embryonic chromatin. The fact that SETDB1 activity is higher in the male pronucleus than in female one has led to the suggestion that it has a role in shaping the sperm-derived naive chromatin (Arney et al., 2002; Liu et al., 2004; Park et al., 2007), although this function is yet to be characterized. Notably, in Drosophila, dSETDB1 alone regulates $\mathrm{H} 3 \mathrm{~K} 9$ trimethylation in pericentric heterochromatin in germarial germline stem cells which generates the oocytes (Clough et al., 2007; Yoon et al., 2008). This function of dSETDB1 is essential for oocyte development in Drosophila, but whether SETDB1 has a similar function in mammalian germline stem cells remains to be elucidated. To explore the function(s) of mammalian SETDB1 in detail, it will be necessary to study embryos in which the SETDB1 activity is maternally depleted, because even the Setdb1null embryo from Setdb1+/ heterozygote cross contains maternally inherited SETDB1 in the cytoplasm.

PML-NB structures are known to be damaged in acute promyelocytic leukemia (APL) patients, in whom PMLRARa fusion protein is produced by chromosomal translocation and the myelocytic differentiation is therefore disturbed (de The et al., 1990). Given the intimate association of SETDB1 with PML and its ability to repress PML-NB-associated genes (Cho et al., 2011), it is possible that SETDB1 participates in the pathogenesis of APL. The PML moiety of the fusion protein might attract SETDB1 to further the repression of PML-RARa-occupied gene promoters (Fig. 2B), which leads to inhibition of transcription even in the presence of physiological levels of retinoic acid (Lin et al., 1999; Minucci and Pelicci, 2006). In a similar context, recent studies have shown that the overexpression of SETDB1 can induce cancer (Ceol et al., 2011; Macgregor et al., 2011; Rodriguez-Paredes et al., 2013) and other diseases (Chase et al., 2013; Ryu et al., 2006; Tan et al., 2012), probably via the downregulation of genes such as tumor suppressor genes. These observations emphasize the importance of achieving the right balance of SETDB1 activity and the dramatic phenotypic consequences of shifts in this balance. A cellular strategy to keep SETDB1 activity in balance might be the force that drives extra exogenous SETDB1 to the cytoplasm, as seen before (Cho et al., 2013).

\section{Acknowledgement}

I thank to $S$. Cho for valuable help and S. Jeong for critical reading of the manuscript. This work was supported by grants from National Research Foundation of Korea of MSIP (2011-0030049, 2012-0006146) and from Rural Development Administration (BioGreen21 Program, PJ009590).

\section{References}

Arney, K.L., Bao, S., Bannister, A.J., Kouzarides, T., and Surani, M.A. (2002). Histone methylation defines 
epigenetic asymmetry in the mouse zygote. Int $\mathrm{J}$ Dev Biol 46, 317-320.

Auman, H.J., Nottoli, T., Lakiza, O., Winger, Q., Donaldson, S., and Williams, T. (2002). Transcription factor AP-2gamma is essential in the extra-embryonic lineages for early postimplantation development. Development 129, 2733-2747.

Ayyanathan, K., Lechner, M.S., Bell, P., Maul, G.G., Schultz, D.C., Yamada, Y., Tanaka, K., Torigoe, K., and Rauscher, F.J., 3rd (2003). Regulated recruitment of HP1 to a euchromatic gene induces mitotically heritable, epigenetic gene silencing: a mammalian cell culture model of gene variegation. Genes Dev 17, 1855-1869.

Bernardi, R., and Pandolfi, P.P. (2007). Structure, dynamics and functions of promyelocytic leukaemia nuclear bodies. Nat Rev Mol Cell Biol 8, 1006-1016.

Billur, M., Bartunik, H.D., and Singh, P.B. (2010). The essential function of HP1 beta: a case of the tail wagging the dog? Trends in biochemical sciences 35, 115-123.

Bilodeau, S., Kagey, M.H., Frampton, G.M., Rahl, P.B., and Young, R.A. (2009). SetDB1 contributes to repression of genes encoding developmental regulators and maintenance of ES cell state. Genes Dev 23, 2484-2489.

Blackburn, M.L., Chansky, H.A., Zielinska-Kwiatkowska, A., Matsui, Y., and Yang, L. (2003). Genomic structure and expression of the mouse ESET gene encoding an ERGassociated histone methyltransferase with a SET domain. Biochimica et biophysica acta 1629, 8-14.

Botuyan, M.V., Lee, J., Ward, I.M., Kim, J.E., Thompson, J.R., Chen, J., and Mer, G. (2006). Structural basis for the methylation state-specific recognition of histone $\mathrm{H} 4$ K20 by 53BP1 and Crb2 in DNA repair. Cell 127, 1361-1373.

Bourc'his, D., and Bestor, T.H. (2004). Meiotic catastrophe and retrotransposon reactivation in male germ cells lacking Dnmt3L. Nature 431, 96-99.

Brower-Toland, B., Riddle, N.C., Jiang, H., Huisinga, K.L., and Elgin, S.C. (2009). Multiple SET methyltransferases are required to maintain normal heterochromatin domains in the genome of Drosophila melanogaster. Genetics 181, 1303-1319.

Cairo, S., De Falco, F., Pizzo, M., Salomoni, P., Pandolfi, P.P., and Meroni, G. (2005). PML interacts with Myc, and Myc target gene expression is altered in PML-null fibroblasts. Oncogene 24, 2195-2203.

Ceol, C.J., Houvras, Y., Jane-Valbuena, J., Bilodeau, S., Orlando, D.A., Battisti, V., Fritsch, L., Lin, W.M., Hollmann, T.J., Ferre, F., et al. (2011). The histone methyltransferase SETDB1 is recurrently amplified in melanoma and accelerates its onset. Nature 471, 513-517.

Chase, K.A., Gavin, D.P., Guidotti, A., and Sharma, R.P. (2013). Histone methylation at H3K9: Evidence for a restrictive epigenome in schizophrenia. Schizophrenia research 149, 15-20.

Chen, C., Nott, T.J., Jin, J., and Pawson, T. (2011). Deciphering arginine methylation: Tudor tells the tale. Nat Rev Mol Cell Biol 12, 629-642.

Cho, G., Lim, Y., and Golden, J.A. (2009). SUMO interaction motifs in Sizn1 are required for promyelocytic leukemia protein nuclear body localization and for transcriptional activation. J Biol Chem 284, 19592-19600.
Cho, S., Park, J.S., and Kang, Y.K. (2011). Dual Functions of Histone-Lysine N-Methyltransferase Setdb1 Protein at Promyelocytic Leukemia-Nuclear Body (PML-NB): Maintaining $P M L-N B$ structure and regulating the expression of its associated genes. J Biol Chem 286, 41115-41124.

Cho, S., Park, J.S., Kwon, S., and Kang, Y.K. (2012). Dynamics of Setdb1 expression in early mouse development. Gene expression patterns : GEP 12, 213-218.

Cho, S.W., Park, J.S., and Kang, Y.K. (2013). Regulated Nuclear Entry of Overexpressed Setdb1. Genes to Cells in press.

Clough, E., Moon, W., Wang, S., Smith, K., and Hazelrigg, T. (2007). Histone methylation is required for oogenesis in Drosophila. Development 134, 157-165.

de The, H., Chomienne, C., Lanotte, M., Degos, L., and Dejean, A. (1990). The $t(15 ; 17)$ translocation of acute promyelocytic leukaemia fuses the retinoic acid receptor alpha gene to a novel transcribed locus. Nature 347 , 558-561.

de The, H., Le Bras, M., and Lallemand-Breitenbach, V. (2012). The cell biology of disease: Acute promyelocytic leukemia, arsenic, and PML bodies. J Cell Biol 198, 11-21.

Dialynas, G.K., Makatsori, D., Kourmouli, N., Theodoropoulos, P.A., McLean, K., Terjung, S., Singh, P.B., and Georgatos, S.D. (2006). Methylationindependent binding to histone $\mathrm{H} 3$ and cell cycledependent incorporation of HP1beta into heterochromatin. J Biol Chem 281, 14350-14360.

Dodge, J.E., Kang, Y.K., Beppu, H., Lei, H., and Li, E. (2004). Histone H3-K9 methyltransferase ESET is essential for early development. Mol Cell Biol 24, 2478-2486.

Figueiredo, M.L., Philip, P., Stenberg, P., and Larsson, J. (2012). HP1a recruitment to promoters is independent of H3K9 methylation in Drosophila melanogaster. PLoS Genet 8, e1003061.

Fritsch, L., Robin, P., Mathieu, J.R., Souidi, M., Hinaux, H., Rougeulle, C., Harel-Bellan, A., Ameyar-Zazoua, M., and Ait-Si-Ali, S. (2010). A subset of the histone H3 lysine 9 methyltransferases Suv39h1, G9a, GLP, and SETDB1 participate in a multimeric complex. Mol Cell 37, 46-56.

Guenther, M.G., Levine, S.S., Boyer, L.A., Jaenisch, R., and Young, R.A. (2007). A chromatin landmark and transcription initiation at most promoters in human cells. Cell 130, 77-88.

Ho, K.L., McNae, I.W., Schmiedeberg, L., Klose, R.J., Bird, A.P., and Walkinshaw, M.D. (2008). MeCP2 binding to DNA depends upon hydration at methyl-CpG. Mol Cell 29, 525-531.

Howard, G., Eiges, R., Gaudet, F., Jaenisch, R., and Eden, A. (2008). Activation and transposition of endogenous retroviral elements in hypomethylation induced tumors in mice. Oncogene 27, 404-408.

Huang, J., Dorsey, J., Chuikov, S., Perez-Burgos, L., Zhang, X., Jenuwein, T., Reinberg, D., and Berger, S.L. (2010). G9a and Glp methylate lysine 373 in the tumor suppressor p53. J Biol Chem 285, 9636-9641.

Huang, Y., Fang, J., Bedford, M.T., Zhang, Y., and Xu, R.M. (2006). Recognition of histone H3 lysine-4 methylation by 
the double tudor domain of JMJD2A. Science 312, 748-751.

Ishov, A.M., Sotnikov, A.G., Negorev, D., Vladimirova, O.V., Neff, N., Kamitani, T., Yeh, E.T., Strauss, J.F., 3rd, and Maul, G.G. (1999). PML is critical for ND10 formation and recruits the PML-interacting protein daxx to this nuclear structure when modified by SUMO-1. J Cell Biol 147, 221-234.

Ivanov, A.V., Peng, H., Yurchenko, V., Yap, K.L., Negorev, D.G., Schultz, D.C., Psulkowski, E., Fredericks, W.J., White, D.E., Maul, G.G., et al. (2007). PHD domainmediated E3 ligase activity directs intramolecular sumoylation of an adjacent bromodomain required for gene silencing. Mol Cell 28, 823-837.

Kamitani, T., Kito, K., Nguyen, H.P., Wada, H., FukudaKamitani, T., and Yeh, E.T. (1998). Identification of three major sentrinization sites in PML. J Biol Chem 273, 26675-26682.

Karimi, M.M., Goyal, P., Maksakova, I.A., Bilenky, M., Leung, D., Tang, J.X., Shinkai, Y., Mager, D.L., Jones, S., Hirst, M., et al. (2011). DNA methylation and SETDB1/ H3K9me3 regulate predominantly distinct sets of genes, retroelements, and chimeric transcripts in mESCs. Cell Stem Cell 8, 676-687.

Kim, T.H., Barrera, L.O., Zheng, M., Qu, C., Singer, M.A., Richmond, T.A., Wu, Y., Green, R.D., and Ren, B. (2005). A high-resolution map of active promoters in the human genome. Nature 436, 876-880.

Lallemand-Breitenbach, V., Zhu, J., Chen, Z., and de The, H. (2012). Curing APL through PML/RARA degradation by As2O3. Trends in molecular medicine 18, 36-42.

Lamprecht, B., Walter, K., Kreher, S., Kumar, R., Hummel, M., Lenze, D., Kochert, K., Bouhlel, M.A., Richter, J., Soler, E., et al. (2010). Derepression of an endogenous long terminal repeat activates the CSF1R protooncogene in human lymphoma. Nature medicine 16, 571-579, 571p following 579.

Lavigne, M., Eskeland, R., Azebi, S., Saint-Andre, V., Jang, S.M., Batsche, E., Fan, H.Y., Kingston, R.E., Imhof, A., and Muchardt, C. (2009). Interaction of HP1 and Brg1/ $\mathrm{Brm}$ with the globular domain of histone $\mathrm{H} 3$ is required for HP1-mediated repression. PLoS Genet 5, e1000769.

Lee, J.S., Haruna, T., Ishimoto, A., Honjo, T., and Yanagawa, S. (1999). Intracisternal type A particlemediated activation of the Notch4/int 3 gene in a mouse mammary tumor: generation of truncated Notch4/int3 mRNAs by retroviral splicing events. Journal of virology 73, 5166-5171.

Lee, J.S., Kim, Y., Kim, I.S., Kim, B., Choi, H.J., Lee, J.M., Shin, H.J., Kim, J.H., Kim, J.Y., Seo, S.B., et al. (2010). Negative regulation of hypoxic responses via induced Reptin methylation. Mol Cell 39, 71-85.

Leung, D.C., and Lorincz, M.C. (2012). Silencing of endogenous retroviruses: when and why do histone marks predominate? Trends in biochemical sciences 37 , 127-133.

Li, H., Rauch, T., Chen, Z.X., Szabo, P.E., Riggs, A.D., and Pfeifer, G.P. (2006). The histone methyltransferase SETDB1 and the DNA methyltransferase DNMT3A interact directly and localize to promoters silenced in cancer cells. J Biol Chem 281, 19489-19500.

Lin, D.Y., Huang, Y.S., Jeng, J.C., Kuo, H.Y., Chang, C.C.,
Chao, T.T., Ho, C.C., Chen, Y.C., Lin, T.P., Fang, H.I., et al. (2006). Role of SUMO-interacting motif in Daxx SUMO modification, subnuclear localization, and repression of sumoylated transcription factors. Mol Cell 24, 341-354.

Lin, R.J., Egan, D.A., and Evans, R.M. (1999). Molecular genetics of acute promyelocytic leukemia. Trends in genetics : TIG 15, 179-184.

Liu, H., Kim, J.M., and Aoki, F. (2004). Regulation of histone $\mathrm{H} 3$ lysine 9 methylation in oocytes and early preimplantation embryos. Development 131, 2269-2280.

Loyola, A., Bonaldi, T., Roche, D., Imhof, A., and Almouzni, G. (2006). PTMs on H3 variants before chromatin assembly potentiate their final epigenetic state. Mol Cell 24, 309-316.

Loyola, A., Tagami, H., Bonaldi, T., Roche, D., Quivy, J.P., Imhof, A., Nakatani, Y., Dent, S.Y., and Almouzni, G. (2009). The HP1alpha-CAF1-SetDB1-containing complex provides $\mathrm{H} 3 \mathrm{~K} 9 \mathrm{me} 1$ for Suv39-mediated $\mathrm{K} 9 \mathrm{me} 3$ in pericentric heterochromatin. EMBO reports 10, 769-775.

Luciani, J.J., Depetris, D., Usson, Y., Metzler-Guillemain, C., Mignon-Ravix, C., Mitchell, M.J., Megarbane, A., Sarda, P., Sirma, H., Moncla, A., et al. (2006). PML nuclear bodies are highly organised DNA-protein structures with a function in heterochromatin remodelling at the G2 phase. J Cell Sci 119, 2518-2531.

Macgregor, S., Montgomery, G.W., Liu, J.Z., Zhao, Z.Z., Henders, A.K., Stark, M., Schmid, H., Holland, E.A., Duffy, D.L., Zhang, M., et al. (2011). Genome-wide association study identifies a new melanoma susceptibility locus at 1q21.3. Nat Genet 43, 1114-1118.

Maksakova, I.A., Romanish, M.T., Gagnier, L., Dunn, C.A., van de Lagemaat, L.N., and Mager, D.L. (2006). Retroviral elements and their hosts: insertional mutagenesis in the mouse germ line. PLoS Genet 2, e2.

Maksakova, I.A., Thompson, P.J., Goyal, P., Jones, S.J., Singh, P.B., Karimi, M.M., and Lorincz, M.C. (2013). Distinct roles of KAP1, HP1 and G9a/GLP in silencing of the two-cell-specific retrotransposon MERVL in mouse ES cells. Epigenetics Chromatin 6, 15.

Martin, C., Beaujean, N., Brochard, V., Audouard, C., Zink, D., and Debey, P. (2006). Genome restructuring in mouse embryos during reprogramming and early development. Dev Biol 292, 317-332.

Matsui, T., Leung, D., Miyashita, H., Maksakova, I.A., Miyachi, H., Kimura, H., Tachibana, M., Lorincz, M.C., and Shinkai, Y. (2010). Proviral silencing in embryonic stem cells requires the histone methyltransferase ESET. Nature 464, 927-931.

Mikkelsen, T.S., Ku, M., Jaffe, D.B., Issac, B., Lieberman, E., Giannoukos, G., Alvarez, P., Brockman, W., Kim, T.K., Koche, R.P., et al. (2007). Genome-wide maps of chromatin state in pluripotent and lineage-committed cells. Nature 448, 553-560.

Minucci, S., and Pelicci, P.G. (2006). Histone deacetylase inhibitors and the promise of epigenetic (and more) treatments for cancer. Nat Rev Cancer 6, 38-51.

Muller, S., Matunis, M.J., and Dejean, A. (1998). Conjugation with the ubiquitin-related modifier SUMO-1 regulates the partitioning of PML within the nucleus. EMBO J 17, 61-70.

Nielsen, A.L., Oulad-Abdelghani, M., Ortiz, J.A., 
Remboutsika, E., Chambon, P., and Losson, R. (2001). Heterochromatin formation in mammalian cells: interaction between histones and HP1 proteins. Mol Cell 7, 729-739.

Ohki, I., Shimotake, N., Fujita, N., Jee, J., Ikegami, T., Nakao, M., and Shirakawa, M. (2001). Solution structure of the methyl-CpG binding domain of human MBD1 in complex with methylated DNA. Cell 105, 487-497.

Pannell, D., Osborne, C.S., Yao, S., Sukonnik, T., Pasceri, P., Karaiskakis, A., Okano, M., Li, E., Lipshitz, H.D., and Ellis, J. (2000). Retrovirus vector silencing is de novo methylase independent and marked by a repressive histone code. EMBO J 19, 5884-5894.

Park, J.S., Jeong, Y.S., Shin, S.T., Lee, K.K., and Kang, Y.K. (2007). Dynamic DNA methylation reprogramming: Active demethylation and immediate remethylation in the male pronucleus of bovine zygotes. Dev Dyn 236, 2523-2533.

Pek, J.W., Anand, A., and Kai, T. (2012). Tudor domain proteins in development. Development 139, 2255-2266.

Peng, J.C., and Karpen, G.H. (2007). H3K9 methylation and RNA interference regulate nucleolar organization and repeated DNA stability. Nat Cell Biol 9, 25-35.

Peters, A.H., Kubicek, S., Mechtler, K., O'Sullivan, R.J., Derijck, A.A., Perez-Burgos, L., Kohlmaier, A., Opravil, S., Tachibana, M., Shinkai, Y., et al. (2003). Partitioning and plasticity of repressive histone methylation states in mammalian chromatin. Mol Cell 12, 1577-1589.

Peters, A.H., O'Carroll, D., Scherthan, H., Mechtler, K., Sauer, S., Schofer, C., Weipoltshammer, K., Pagani, M., Lachner, M., Kohlmaier, A., et al. (2001). Loss of the Suv39h histone methyltransferases impairs mammalian heterochromatin and genome stability. Cell 107, 323-337.

Rathert, P., Dhayalan, A., Murakami, M., Zhang, X., Tamas, R., Jurkowska, R., Komatsu, Y., Shinkai, Y., Cheng, X., and Jeltsch, A. (2008). Protein lysine methyltransferase G9a acts on non-histone targets. Nature chemical biology 4, 344-346.

Rea, S., Eisenhaber, F., O'Carroll, D., Strahl, B.D., Sun, Z.W., Schmid, M., Opravil, S., Mechtler, K., Ponting, C.P., Allis, C.D., et al. (2000). Regulation of chromatin structure by site-specific histone $\mathrm{H} 3$ methyltransferases. Nature 406, 593-599.

Rodriguez-Paredes, M., Martinez de Paz, A., SimoRiudalbas, L., Sayols, S., Moutinho, C., Moran, S., Villanueva, A., Vazquez-Cedeira, M., Lazo, P.A., Carneiro, F., et al. (2013). Gene amplification of the histone methyltransferase SETDB1 contributes to human lung tumorigenesis. Oncogene.

Rossant, J. (2004). Lineage development and polar asymmetries in the peri-implantation mouse blastocyst. Seminars in cell \& developmental biology 15, 573-581.

Ryu, H., Lee, J., Hagerty, S.W., Soh, B.Y., McAlpin, S.E., Cormier, K.A., Smith, K.M., and Ferrante, R.J. (2006). ESET/SETDB1 gene expression and histone H3 (K9) trimethylation in Huntington's disease. Proceedings of the National Academy of Sciences of the United States of America 103, 19176-19181.

Santos, F., Peters, A.H., Otte, A.P., Reik, W., and Dean, W. (2005). Dynamic chromatin modifications characterise the first cell cycle in mouse embryos. Dev Biol 280, 225-236.
Sarraf, S.A., and Stancheva, I. (2004). Methyl-CpG binding protein MBD1 couples histone $\mathrm{H} 3$ methylation at lysine 9 by SETDB1 to DNA replication and chromatin assembly. Mol Cell 15, 595-605.

Schotta, G., Ebert, A., Krauss, V., Fischer, A., Hoffmann, J., Rea, S., Jenuwein, T., Dorn, R., and Reuter, G. (2002). Central role of Drosophila SU(VAR)3-9 in histone H3-K9 methylation and heterochromatic gene silencing. Embo $\mathrm{J}$ 21, 1121-1131.

Schultz, D.C., Ayyanathan, K., Negorev, D., Maul, G.G., and Rauscher, F.J., 3rd (2002). SETDB1: a novel KAP-1associated histone $\mathrm{H} 3$, lysine 9-specific methyltransferase that contributes to HP1-mediated silencing of euchromatic genes by KRAB zinc-finger proteins. Genes Dev 16, 919-932.

Seeler, J.S., Marchio, A., Sitterlin, D., Transy, C., and Dejean, A. (1998). Interaction of SP100 with HP1 proteins: a link between the promyelocytic leukemiaassociated nuclear bodies and the chromatin compartment. Proceedings of the National Academy of Sciences of the United States of America 95, 7316-7321.

Shen, T.H., Lin, H.K., Scaglioni, P.P., Yung, T.M., and Pandolfi, P.P. (2006). The mechanisms of PML-nuclear body formation. Mol Cell 24, 331-339.

Siomi, M.C., Mannen, T., and Siomi, H. (2010). How does the royal family of Tudor rule the PIWI-interacting RNA pathway? Genes Dev 24, 636-646.

Stielow, B., Sapetschnig, A., Wink, C., Kruger, I., and Suske, G. (2008). SUMO-modified Sp3 represses transcription by provoking local heterochromatic gene silencing. EMBO reports 9, 899-906.

Strumpf, D., Mao, C.A., Yamanaka, Y., Ralston, A., Chawengsaksophak, K., Beck, F., and Rossant, J. (2005). Cdx2 is required for correct cell fate specification and differentiation of trophectoderm in the mouse blastocyst. Development 132, 2093-2102.

Tachibana, M., Nozaki, M., Takeda, N., and Shinkai, Y. (2007). Functional dynamics of H3K9 methylation during meiotic prophase progression. Embo J 26, 3346-3359.

Tachibana, M., Sugimoto, K., Nozaki, M., Ueda, J., Ohta, T., Ohki, M., Fukuda, M., Takeda, N., Niida, H., Kato, H., et al. (2002). G9a histone methyltransferase plays a dominant role in euchromatic histone $\mathrm{H} 3$ lysine 9 methylation and is essential for early embryogenesis. Genes Dev 16, 1779-1791.

Tachibana, M., Ueda, J., Fukuda, M., Takeda, N., Ohta, T., Iwanari, H., Sakihama, T., Kodama, T., Hamakubo, T., and Shinkai, Y. (2005). Histone methyltransferases G9a and GLP form heteromeric complexes and are both crucial for methylation of euchromatin at H3-K9. Genes Dev 19, 815-826.

Tan, S.L., Nishi, M., Ohtsuka, T., Matsui, T., Takemoto, K., Kamio-Miura, A., Aburatani, H., Shinkai, Y., and Kageyama, R. (2012). Essential roles of the histone methyltransferase ESET in the epigenetic control of neural progenitor cells during development. Development 139, 3806-3816.

Taverna, S.D., Li, H., Ruthenburg, A.J., Allis, C.D., and Patel, D.J. (2007). How chromatin-binding modules interpret histone modifications: lessons from professional pocket pickers. Nat Struct Mol Biol 14, 1025-1040.

Thiru, A., Nietlispach, D., Mott, H.R., Okuwaki, M., Lyon, 
D., Nielsen, P.R., Hirshberg, M., Verreault, A., Murzina, N.V., and Laue, E.D. (2004). Structural basis of HP1/ PXVXL motif peptide interactions and HP1 localisation to heterochromatin. EMBO J 23, 489-499.

Tsumura, A., Hayakawa, T., Kumaki, Y., Takebayashi, S., Sakaue, M., Matsuoka, C., Shimotohno, K., Ishikawa, F., Li, E., Ueda, H.R., et al. (2006). Maintenance of selfrenewal ability of mouse embryonic stem cells in the absence of DNA methyltransferases Dnmt1, Dnmt3a and Dnmt3b. Genes Cells 11, 805-814.

Ueda, J., Tachibana, M., Ikura, T., and Shinkai, Y. (2006). Zinc finger protein Wiz links G9a/GLP histone methyltransferases to the co-repressor molecule CtBP. J Biol Chem 281, 20120-20128.

Verschure, P.J., van der Kraan, I., de Leeuw, W., van der Vlag, J., Carpenter, A.E., Belmont, A.S., and van Driel, R. (2005). In vivo HP1 targeting causes large-scale chromatin condensation and enhanced histone lysine methylation. Mol Cell Biol 25, 4552-4564.

Walsh, C.P., Chaillet, J.R., and Bestor, T.H. (1998). Transcription of IAP endogenous retroviruses is constrained by cytosine methylation. Nat Genet 20, 116-117.

Wang, H., An, W., Cao, R., Xia, L., Erdjument-Bromage, H., Chatton, B., Tempst, P., Roeder, R.G., and Zhang, Y. (2003). mAM facilitates conversion by ESET of dimethyl to trimethyl lysine 9 of histone $\mathrm{H} 3$ to cause transcriptional repression. Mol Cell 12, 475-487.

Wang, Z.G., Delva, L., Gaboli, M., Rivi, R., Giorgio, M., Cordon-Cardo, C., Grosveld, F., and Pandolfi, P.P. (1998a). Role of PML in cell growth and the retinoic acid pathway. Science 279, 1547-1551.

Wang, Z.G., Ruggero, D., Ronchetti, S., Zhong, S., Gaboli, M., Rivi, R., and Pandolfi, P.P. (1998b). PML is essential for multiple apoptotic pathways. Nat Genet 20, 266-272.
Wolff, B., Sanglier, J.J., and Wang, Y. (1997). Leptomycin B is an inhibitor of nuclear export: inhibition of nucleocytoplasmic translocation of the human immunodeficiency virus type 1 (HIV-1) Rev protein and Rev-dependent mRNA. Chem Biol 4, 139-147.

Yang, L., Xia, L., Wu, D.Y., Wang, H., Chansky, H.A., Schubach, W.H., Hickstein, D.D., and Zhang, Y. (2002). Molecular cloning of ESET, a novel histone H3-specific methyltransferase that interacts with ERG transcription factor. Oncogene 21, 148-152.

Yeap, L.S., Hayashi, K., and Surani, M.A. (2009). ERGassociated protein with SET domain (ESET)-Oct4 interaction regulates pluripotency and represses the trophectoderm lineage. Epigenetics Chromatin 2, 12.

Yoder, J.A., Walsh, C.P., and Bestor, T.H. (1997). Cytosine methylation and the ecology of intragenomic parasites. Trends in genetics : TIG 13, 335-340.

Yoon, J., Lee, K.S., Park, J.S., Yu, K., Paik, S.G., and Kang, Y.K. (2008). dSETDB1 and SU(VAR)3-9 sequentially function during germline-stem cell differentiation in Drosophila melanogaster. PLoS ONE 3, e2234.

Yuan, P., Han, J., Guo, G., Orlov, Y.L., Huss, M., Loh, Y.H., Yaw, L.P., Robson, P., Lim, B., and Ng, H.H. (2009). Eset partners with Oct4 to restrict extraembryonic trophoblast lineage potential in embryonic stem cells. Genes \& development 23, 2507-2520.

Zhao, T., Heyduk, T., Allis, C.D., and Eissenberg, J.C. (2000). Heterochromatin protein 1 binds to nucleosomes and DNA in vitro. J Biol Chem 275, 28332-28338.

Zhong, S., Muller, S., Ronchetti, S., Freemont, P.S., Dejean, A., and Pandolfi, P.P. (2000). Role of SUMO-1modified PML in nuclear body formation. Blood 95, 2748-2752. 


\section{Microbiology / Molecular Biology}

Caister Academic Press is a leading academic publisher of advanced texts in microbiology, molecular biology and medical research. Full details of all our publications at caister.com

- Cyanobacteria: Omics and Manipulation Edited by: DA Los (2017) www.caister.com/cyano3

- Brain-eating Amoebae: Biology and Pathogenesis of Naegleria fowleri

Author: R Siddiqui, IKM Ali, JR Cope, et al. (2016)

"explains the current knowledge and research" (ProtoView) www.caister.com/naegleria

- Foot and Mouth Disease Virus: Current Research and Emerging Trends

Edited by: F Sobrino, E Domingo (2017)

www.caister.com/fmdv

- Staphylococcus: Genetics and Physiology

Edited by: GA Somerville (2016)

www.caister.com/staph2

- Chloroplasts: Current Research and Future Trends Edited by: H Kirchhoff (2016)

www.caister.com/chloroplasts

- Microbial Biodegradation: From Omics to Function and Application

Edited by: J Długoński (2016)

www.caister.com/biodegradation

- Influenza: Current Research

Edited by: Q Wang, YJ Tao (2016)

www.caister.com/flu3

- MALDI-TOF Mass Spectrometry in Microbiology Edited by: M Kostrzewa, S Schubert (2016)

www.caister.com/malditof

- Aspergillus and Penicillium in the Post-genomic Era Edited by: RP Vries, IB Gelber, MR Andersen (2016)

"new and well-presented book" (IMA Fungus)

www.caister.com/aspergillus2

- The Bacteriocins: Current Knowledge and Future

Prospects

Edited by: RL Dorit, SM Roy, MA Riley (2016)

www.caister.com/bacteriocins

- Omics in Plant Disease Resistance

Edited by: V Bhadauria (2016)

"essential reading ... highly recommended" (Biotechnol. Agron.

Soc. Environ.)

www.caister.com/opdr

- Acidophiles: Life in Extremely Acidic Environments

Edited by: R Quatrini, DB Johnson (2016)

"Contributors from a wide range of biological and environmental sciences" (ProtoView)

www.caister.com/acidophiles
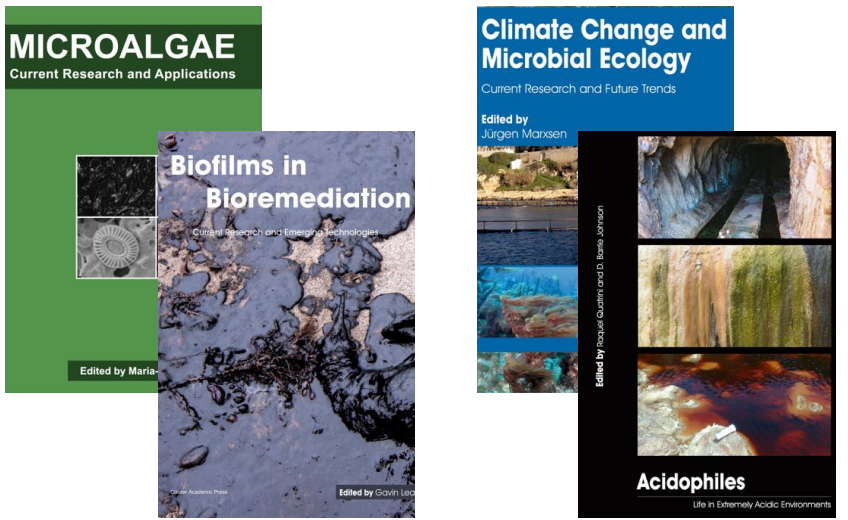
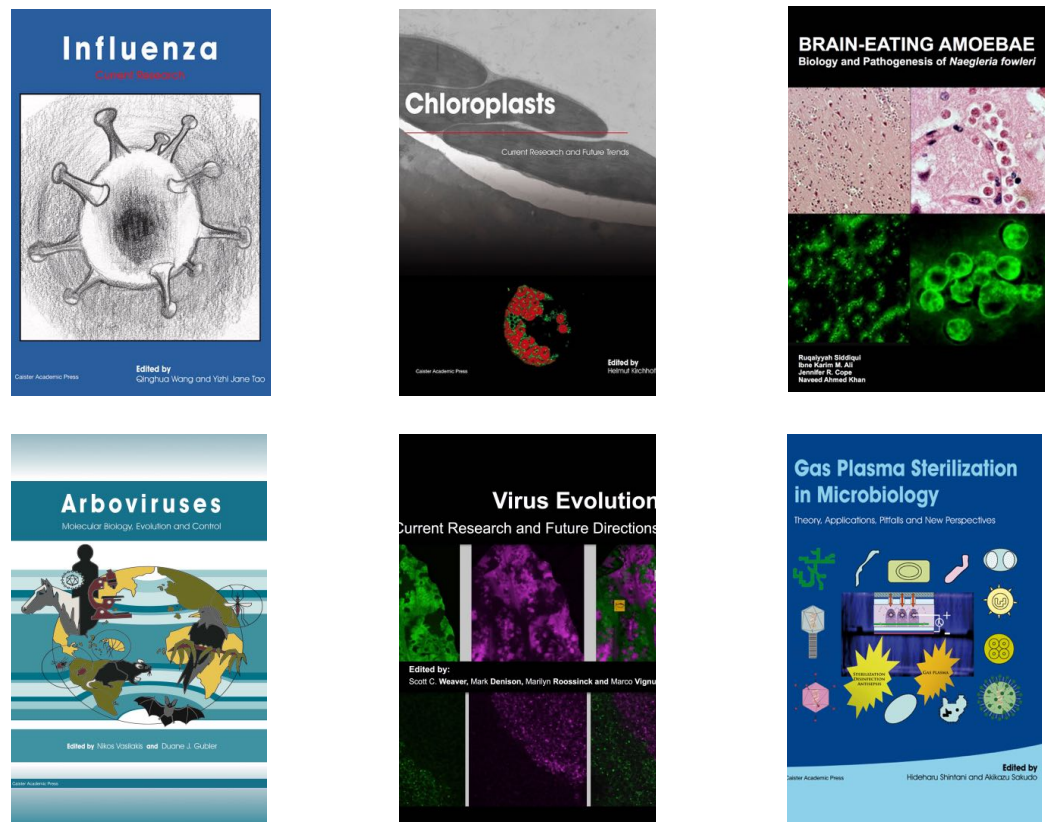

- Climate Change and Microbial Ecology: Current Research and Future Trends

Edited by: J Marxsen (2016)

"impressive" (ASM: Small Things Considered); "written at a high scientific level" (BioSpektrum)

www.caister.com/climate

- Biofilms in Bioremediation: Current Research and Emerging Technologies

Edited by: G Lear (2016)

"describes explicitly the role of biofilms in bioremediation" (Biospektrum); indispensable ... recommended (Biotechnol. Agron. Soc. Environ.) www.caister.com/biorem

- Microalgae: Current Research and Applications

Edited by: MN Tsaloglou (2016)

www.caister.com/microalgae

- Gas Plasma Sterilization in Microbiology: Theory, Applications, Pitfalls and New Perspectives

Edited by: H Shintani, A Sakudo (2016)

"a nice state of the art compilation" (Doodys)

www.caister.com/gasplasma

- Virus Evolution: Current Research and Future Directions Edited by: SC Weaver, M Denison, M Roossinck, et al. (2016) "highly informative ... a pleasure to read" (Microbiol. Today) www.caister.com/virusevol

- Arboviruses: Molecular Biology, Evolution and Control Edited by: N Vasilakis, DJ Gubler (2016)

"a thorough and compelling review ... an outstanding book ... highly recommended" (Am. J. Trop. Med. Hyg.) www.caister.com/arbo

- Shigella: Molecular and Cellular Biology

Edited by: WD Picking, WL Picking (2016)

www.caister.com/shigella

- Aquatic Biofilms: Ecology, Water Quality and Wastewater Treatment

Edited by: AM Romaní, H Guasch, MD Balaguer (2016)

"essential reference book" (Biotechnol. Agron. Soc. Environ.)

www.caister.com/aquaticbiofilms

- Alphaviruses: Current Biology

Edited by: S Mahalingam, L Herrero, B Herring (2016)

"up-to-date review of the field" (Aus. Vet. J.)

www.caister.com/alpha 